\title{
A Class of Numerical Algorithm for Impact Degree Assessment of Emergency Systems
}

\author{
Yuwen Chang, Yifan Gao, Jiexin Yi, Wei Yan, Changbo Geng, and Song Zhang
}

Research Institute of Petroleum Exploration and Development, PetroChina, Beijing 100083, China

Correspondence should be addressed to Wei Yan; yanwei123456@petrochina.com.cn

Received 16 February 2013; Revised 2 May 2013; Accepted 7 May 2013

Academic Editor: Chong Lin

Copyright ( 2013 Yuwen Chang et al. This is an open access article distributed under the Creative Commons Attribution License, which permits unrestricted use, distribution, and reproduction in any medium, provided the original work is properly cited.

\begin{abstract}
A standard procedure for the evaluation of emergency impact is developed, concentrating on variation of the impact degree. A numerical method is presented in this paper. The concepts of impact depth and impact width are introduced to assess the impact degree, and both of which determine the evolution path of impact. Based on the variation pattern of impact depth, the evolution path could be divided into rising stage, plateau stage, and recession stage, and path of each stage could be expressed in terms of specified functions. The major goal of this procedure is to measure the emergency impact and make predictions for the consequences. In the case study, we applied this procedure to the analysis of the impact caused by 3.11 earthquake in Japan and demonstrated the algorithm's effectiveness and feasibility. Although this methodology shows improvement in quantitative analysis of the emergency impact, the accuracy of the impact path and the derivative effect of secondary derivative events are issues that yet to be further studied.
\end{abstract}

\section{Introduction}

The emergency refers to an event that is unanticipated and also hard to be prevented [1-3]. Due to the complexity and high uncertainty, emergency requires a timely decisionmaking process and unconventional methods to deal with [47].

During recent years, the development course of emergency was investigated quite intensively; a number of researchers emphasized explaining how the mechanism functions. Li et al. [8], from the systematic perspective, proposed that the unconventional nature of the emergency is generated by the energy exchange between system and environment, which have much in common with the mechanism of microparticle movement. Cozzani et al. [9] constructed a systematic procedure in order to quantitatively assess the risk derived from domino effect, which is accomplished by calculating the propagation probability of primary scenarios and the expected frequencies of domino events. Although this methodology is mainly designed for complex plant layouts, it has been a turning point in quantitative research on unanticipated events. Ji et al. [10] also provided attention to domino effects and introduced the concept of "event chain" to describe the occurrence of a sequence of derivative events. By calculating the probability of occurrence and the possible consequences of each scenario, the comprehensive risk of a selected scene could be assessed.

A lot of efforts are being spent on the research on emergency; however, an effective way of evaluating the impact caused by emergency has yet to be developed. Ju and Wang [11] attempted to quantify the extent of emergency impact according to normalized formula of catastrophe theory. Unfortunately, this method failed to illustrate the changing process of emergency impact. Fink [12] stated that influence caused by a crisis usually has five development stages: gestation, outbreak, spread, treatment, and sequelae. At each stage, the crisis impact demonstrates different traits. Therefore, the impact degree of an emergency is changing and needs to be evaluated with consideration of the feature of each stage [13-15].

A major goal of this paper is to develop a standard procedure to measure the emergency impact and make predictions for the consequences. In the next section, relevant concepts are defined, and the assessment procedure is described; Section 3 applies this procedure to the analysis of the impact caused by 3.11 earthquake in Japan and predicts Japan's oil 
consumption in the future; Section 4 gives the conclusions and future directions of research.

\section{A Numerical Method for Assessment of Emergency Impact Degree}

2.1. Radiation Effects and Derivative Events. In most cases, an emergency is characterized by complexity, unpredictability, and perniciousness $[16,17]$. Moreover, with the deepening of global integration and the immense impetus of information technology, the impact derived from an emergency tends to extend outward, which is described as radiation effects. Once certain boundaries were reached, new events will be triggered.

In the mechanism of radiation effect, the emergency functions as a "field source," diffusing its influence through interaction between social factors (Figure 1). As time goes by, nevertheless, the radiation effect will be counteracted, and the events triggered by radiation effect will gradually restore to the original state, while sometimes specified events may bring about a permanent impact (nuclear spill).

The new event triggered by emergency radiation effects is defined as derivative event. In this papers we focus on the primary derivative events directly triggered by emergency and secondary derivative events triggered by the primary derivative events. To facilitate the analysis, we assume here that there is no cross-impact among the derivative events of the same level.

\subsection{Impact Depth and Impact Width}

2.2.1. Impact Depth. The state of a derivative event changes as a result of the emergency radiation effect, and the concept of impact depth is introduced to measure this change:

$$
\eta=\frac{\mu_{0}-\mu_{t}}{\mu_{0}},
$$

where $\eta$ is impact depth, $\mu_{t}$ is the state of the derivative event at time $t$ after the occurrence of an emergency, and $\mu_{0}$ represents the reference state prior to the emergency.

(i) $\eta>0$, the derivative event is in the state of contraction;

(ii) $\eta<0$, the derivative event is in the state of expansion;

(iii) $\eta=0$, the derivative event has been restored to the state prior to the emergency.

Whatever the direction of change at the beginning, the absolute value of $\eta$ would gradually reduce and approach zero. During this process, the impact on the derivative events decays.

2.2.2. Impact Width. Impact width is a measure of the time scope representing the period in which the emergency impact lasts. Duration of an emergency may be fairly short, while its influence could last a long time. For instance, an earthquake

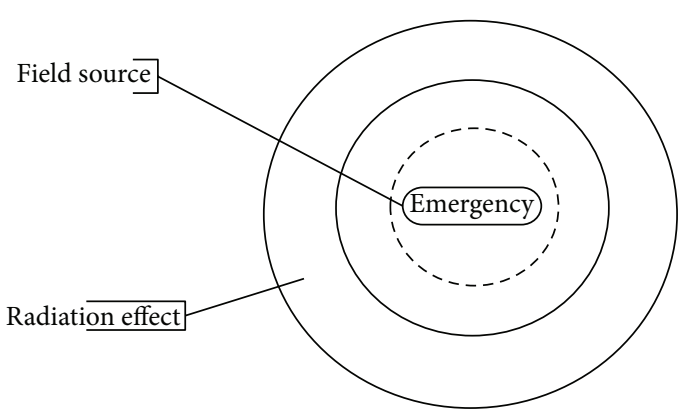

FIGURE 1: Emergency radiation.

usually lasts only a few minutes, but it takes a long time to recover the loss. In general, events of different types show obvious divergence in impact width; notwithstanding, the same event, under different conditions, may also demonstrate different impact width.

\subsection{Evolution Path of Impact}

2.3.1. Trend and Fluctuation. When an emergency triggers a derivative event, this means that the emergency leads to a change in the derivative event. This change consists of two parts, trend and fluctuation. The trend represents the general direction in which the derivative event tends to move, while the fluctuation refers to temporary volatility.

In our study about the impact degree of emergency, the focus is on the impact's long-term movement, that is, we are concerned with the trend of the emergency impact, not fluctuations. This is based on the consideration that the fluctuation is transient, which will not last long, even if the fluctuation may move in an opposite direction compared to the trend during a certain period, it is unlikely to have material effect on the trend.

Taking into account the above discussion, our study puts more emphasis on analyzing the trend of the emergency impact. The method established in this paper aims to illustrate and quantify the evolution route of the emergency impact and further to make a judgment on the derivative event's future movement pattern after being impacted by the emergency.

2.3.2. Impact Path and Functions. Emergency could be viewed as a complex system, actually, it does. However, the impact path associated with the emergency, in our view, has certain regularity in its changing process. We assume that the evolution process of the emergency impact, similar to a product life cycle [18] comprised of growth period, maturity period, and decline period, will go through rising stage, plateau stage, and recession stage.

Combining the impact depth and width, the evolution path of emergency impact could be determined. Taking $\eta \geq$ 0 as an example, in Figure 2, the horizontal axis represents impact width, a measure of the time horizon of emergency impact; the vertical axis represents impact depth, a measure of change in derivative events. 
TABLE 1: Functions of impact path.

\begin{tabular}{lcc}
\hline Evolution paths & Time scope & Functions \\
\hline Rising stage & {$\left[0, T_{1}\right]$} & $\eta=a t^{b}+c(b>1)$ \\
Plateau stage & {$\left[T_{1}, T_{2}\right]$} & $\eta=\eta_{0}$ \\
Recession stage & {$\left[T_{2}, T_{n}\right]$} & $\eta=a e^{b t}+c(b<0)$ \\
\hline
\end{tabular}

(i) Rising stage $\left(\left[0, T_{1}\right]\right)$, at which the impact depth increases rapidly, indicating emergency impact is growing.

(ii) Plateau stage $\left(\left[T_{1}, T_{2}\right]\right)$, at which the impact depth almost maintains at a certain level, indicating emergency impact is under control or has reached its limit.

(iii) Recession stage $\left(\left[T_{2}, T_{n}\right]\right)$, at which the impact depth shows a downward trend, indicating emergency impact gradually decays.

To accurately assess the degree of impact extent, the following functions are employed to quantify the evolution path of each stage (Table 1).

The rising stage is described by an exponential function, reflecting the growing trend of the impact depth; at the plateau stage, the impact is stable and keeps at a constant level; the declining stage is described by a power function, reflecting the declining route of the impact depth.

These functions seem to be too simple to explain complicated things like emergency; however, they are, in essence, capable of depicting the shape of rising trend and downtrend of the evolvement route of emergency impact. The simpleness of the form does not hamper our evaluation and judgment on the future trend of the emergency impact.

2.3.3. Special Cases. In most cases, the evolution path of impact includes all three stages above; nevertheless, there are two special cases which are worthy of attention.

(1) Special Case 1 (a Convulsive Event). The impact caused by a convulsive event could reach the highest level within a short time, and then immediately shift to the recession state. Thus, the impact path of such event only consists of two stages ( see Figure 3):

(i) rising stage $\left(\left[0, T_{1}\right]\right)$, at which the impact depth increases rapidly, and the curve shows a steep upward trend;

(ii) recession stage $\left(\left[T_{1}, T_{n}\right]\right)$, at which the impact depth begins to decline due to the decaying influence, and the curve shows a downward trend approaching zero.

For convulsive events, functions of impact evolution paths are as shown in Table 2.

(2) Special Case 2 (an Event with Persistent Impact). The influence caused by some events will not decay with the passage of time, and evolution path of impact of such event consists of a rising stage and a plateau stage (see Figure 4):

(i) rising stage $\left(\left[0, T_{1}\right]\right)$, at which the impact depth increases until $T_{1}$; (ii) plateau stage $\left(\left[T_{1}, T_{n}\right]\right)$, at which the impact depth keeps at a constant level, and the path is a horizontal line.

For events with persistent effects, functions are as shown in Table 3.

2.4. Assessment Algorithm of Emergency Impact. As depicted in Figure 5, this assessment procedure comprises two parts: assessment of the impact on primary derivative events and assessment of the impact on secondary derivative events.

2.4.1. Calculation Procedure for Primary Derivative Event. The primary derivative event is directly triggered by an emergency; thus, the change of its state is closely associated with the evolution path of impact. The assessment is summarized in the following steps:

(i) identification of the emergency and primary derivative event;

(ii) assessment of the depth, width, and evolution path of emergency impact;

(iii) prediction of the development trend of primary derivative event.

2.4.2. Calculation Procedure for Secondary Derivative Event. Emergency radiation effect is not merely limited to the primary derivative event. In most cases, primary derivative events would give birth to secondary derivative events.

The assessment is summarized in the following steps:

(i) assessment of the impact on the primary derivative event (Section 2.4.1);

(ii) establishment of a linkage mechanism between primary derivative event and secondary derivative event, which is achieved by constructing econometric models;

(iii) prediction of the development trend of secondary derivative event.

\section{Case Studies}

3.1. Background. On March 11, 2011, a massive 8.8 magnitude quake hit the northeast coast of Japan, causing heavy losses. Consequently, Japan's major industrial base, located in Kanto, was severely damaged and a number of factories ran into trouble. What is more, nuclear leaks brought about a worldwide concern for nuclear safety; hence, Japan's nuclear policy is confronted with a complete adjustment. From the standpoint of energy consumption, the damage to industrial production and change in nuclear policy will both have a profound impact on Japan's oil demand.

In this section, "3.11 earthquake in Japan" is regarded as an emergency, "industrial production" and "nuclear utilization" are identified as primary derivative events, and "demand for oil" is viewed as a secondary event triggered by the change of primary derivative events. As per the assessment procedure built in Section 2, we make a prejudgment of Japan's oil demand from March, 2011 to October, 2012. 


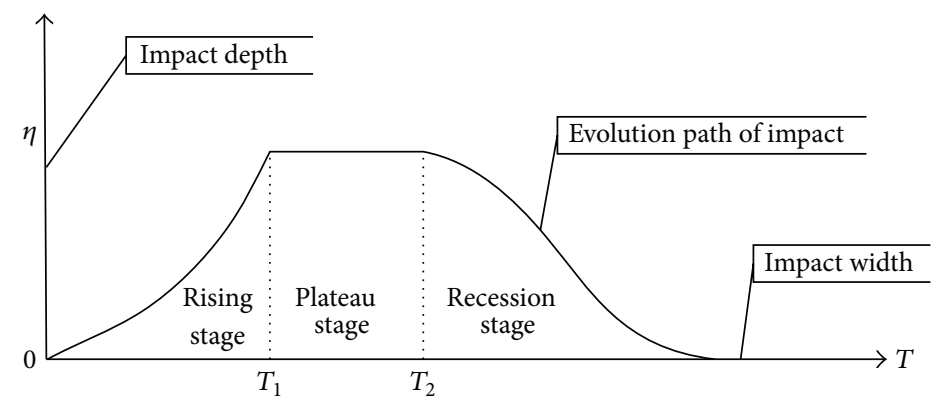

FIgURE 2: General type of emergency impact evolution path.

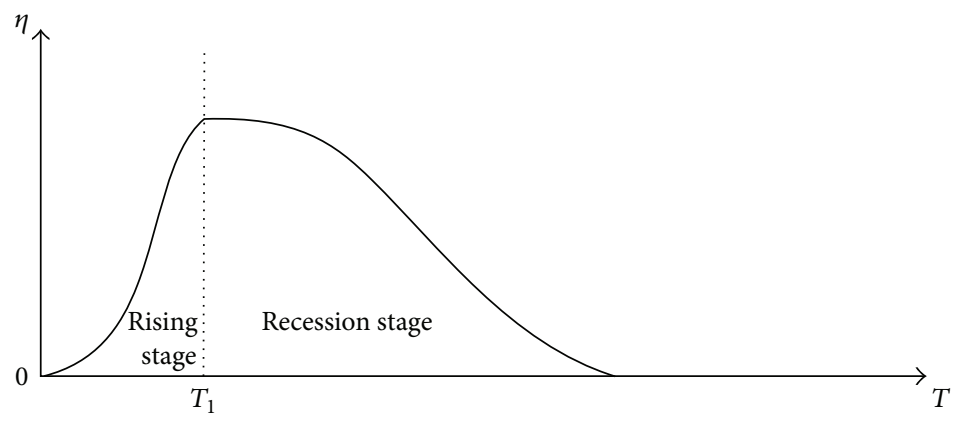

FIGURE 3: Impact evolution path of convulsive event.

TABLE 2: Functions of impact path.

\begin{tabular}{lcc}
\hline Evolution paths & Time scope & Functions \\
\hline Rising stage & {$\left[0, T_{1}\right]$} & $\eta=a t^{b}+c(b>1)$ \\
Recession stage & {$\left[T_{1}, T_{n}\right]$} & $\eta=a e^{b t}+c(b<0)$ \\
\hline
\end{tabular}

\subsection{Evaluation of Impact on Primary Derivative Events}

3.2.1. Impact on Japan's Industrial Production. Due to the destructive effect on yield capacity, Japan's industrial added value in March diminished approximately $10 \%$ compared to that in February and kept growing after April. Hence, it could be deemed that the evolutionary path of impact on industrial production is at the recession stage, and the function of the path at this stage is expressed as $\eta=a e^{b t}+c(b<0)$. With historical data, the function could be figured out:

$$
\eta=0.28 e^{-0.36 t}
$$

We can derive

$$
\mu_{t}=\mu_{0}-\eta * \mu_{0}
$$

from (1). Then by combining (2) and (3), the trend of Japan's industrial added value could be predicted (see Figure 6).

3.2.2. Path of Impact on Japan's Nuclear Utilization. For the hidden peril of nuclear power, Japan will stand a good chance of limiting the nuclear capacity in the future. Thus, it could be deemed that the evolution path of impact on the nuclear utilization is at the rising stage, and the function of path could
TABLE 3: Functions of impact paths.

\begin{tabular}{lcc}
\hline Evolution paths & Time scope & Functions \\
\hline Rising stage & {$\left[0, T_{1}\right]$} & $\eta=a t^{b}+c(b>1)$ \\
Plateau stage & {$\left[T_{1}, T_{n}\right]$} & $\eta=\eta_{0}$ \\
\hline
\end{tabular}

be expressed as $\eta=a x^{b}+c(b>1)$. Taking account of Japan's strategic planning on energy development and the feasibility of employing nuclear power, we make an assumption here that till Oct. 2012, Japan's demand for nuclear power would decrease by $30 \%$ than that in Feb, 2011, and then the impact path of this stage is figured out:

$$
\eta=0.005 t^{1.39}+0.18
$$

The consumption of nuclear power in February, 2011 determines that $\mu_{0}=23,250,000,000 \mathrm{KWH}$. By incorporating (2) and (4), the monthly amount of reduction in Japan's demand for nuclear energy is shown in Figure 7.

Figure 8 presents the historical trend of Japan's oil consumption and industry added value, based on which the linkage mechanism (5) between those two could be derived:

$$
\mathrm{OC}_{\mathrm{IV}}=e^{7.8+0.0121 \mathrm{IV}}
$$

where $\mathrm{OC}_{\mathrm{IV}}$ is the oil consumed in industrial production, and IV is industrial added value.

3.2.3. Impact of Nuclear Energy Utilization on Oil Demand. According to Japan's current energy consumption, it could 


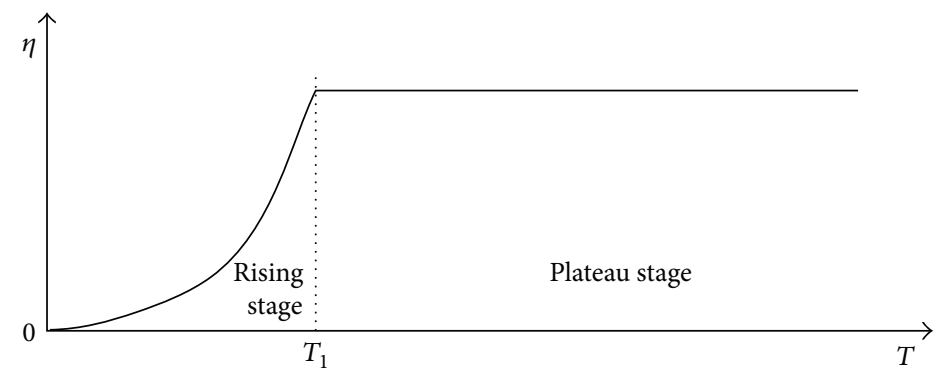

FIgURE 4: Impact evolution path of persistent emergency.

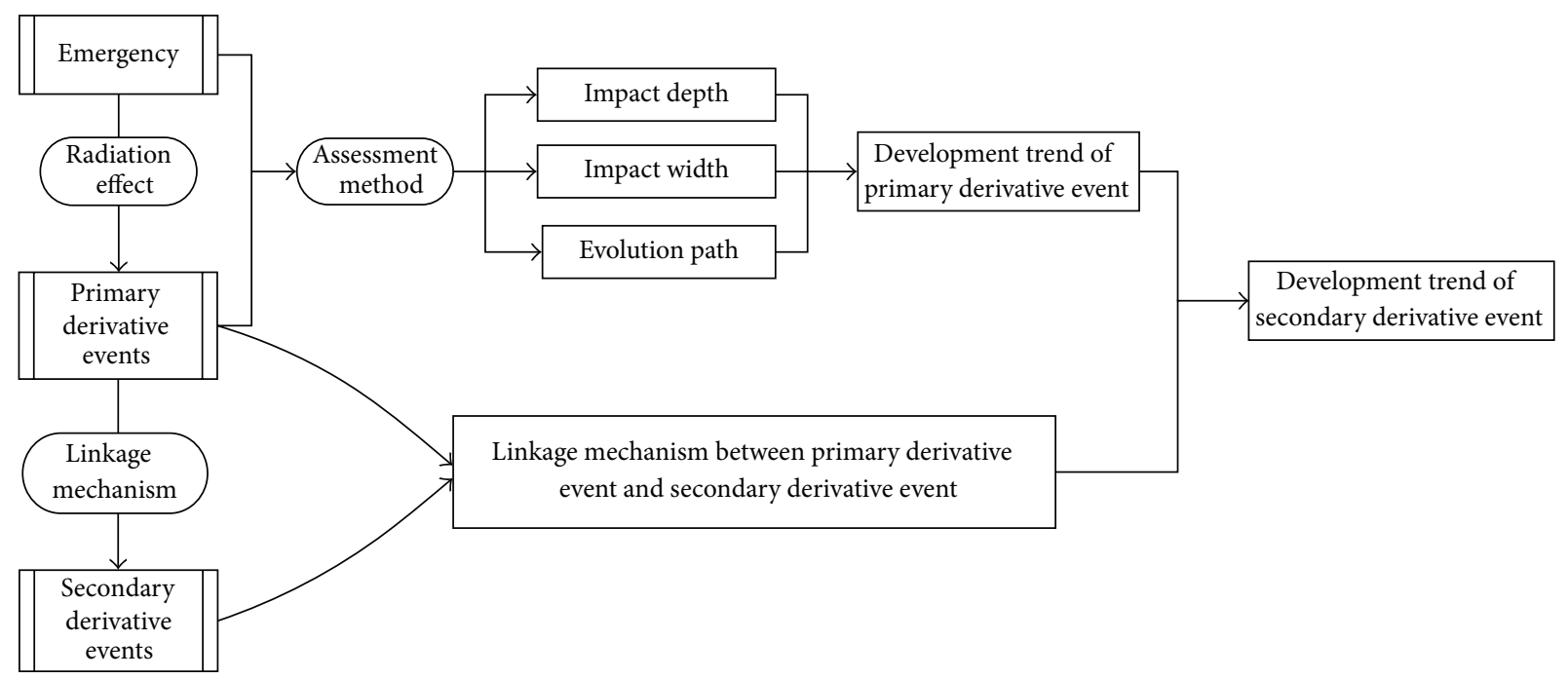

FIGURE 5: Assessment process of emergency impact.

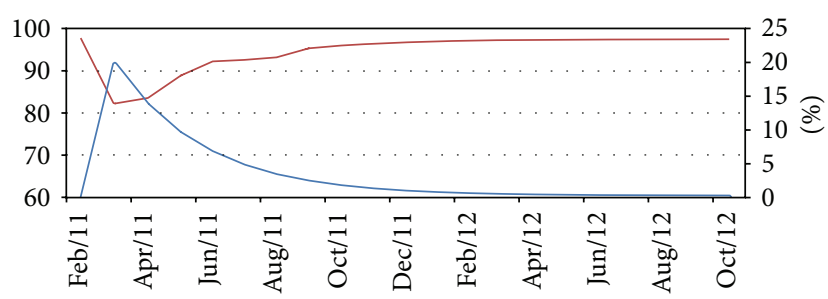

- Industrial added value $(2005=100)$

— Depth of impact on industrial added value

FIGURE 6: Industry added value and impact depth.

be believed that $50 \%$ of the reduced nuclear energy will be substituted by oil:

$$
\mathrm{OC}_{\mathrm{NU}}=0.5 \mathrm{NU}
$$

where $\mathrm{OC}_{\mathrm{NU}}$ is the oil consumption that substitutes for nuclear energy, $\mathrm{NU}$ is the reduction in the demand for nuclear energy. Hence, $\mathrm{OC}_{\mathrm{NU}}$ could be calculated on the basis of (4) and (6).

3.3. Trend of Oil Consumption after the Earthquake. The following equation is presented under the assumption that

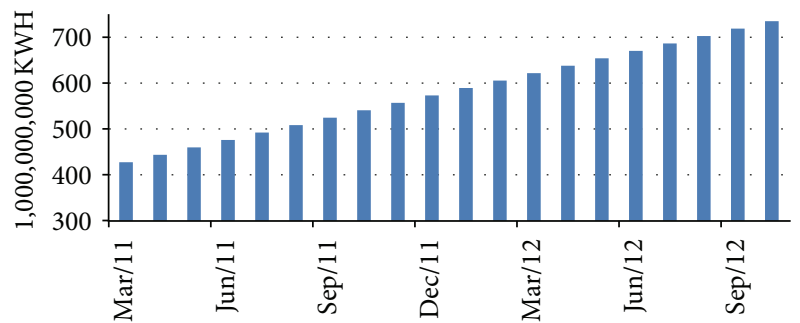

Figure 7: Amount of reduction in Japan's demand for nuclear energy.

the proportion of industrial oil consumption from Japan's total oil consumption remains the same during the period in which this prediction is made:

$$
\mathrm{OC}=\frac{1}{\lambda} \cdot \mathrm{OC}_{\mathrm{IV}}+\mathrm{OC}_{\mathrm{NU}}
$$

where $\lambda$ is the proportion of industrial oil consumption from Japan's total oil consumption, according to statistics from EIA, $\lambda=0.4$. Figure 9 shows the comparison between the forecast trend and real trend of Japan's oil demand. 


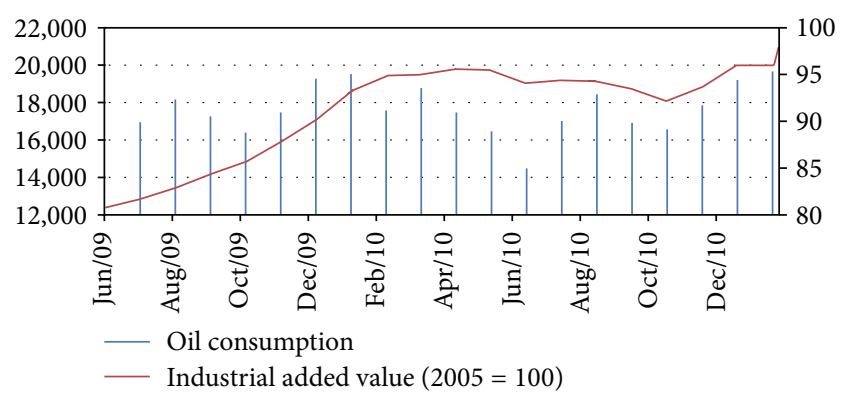

FIgURE 8: Oil consumption and historical trend of industry added value.

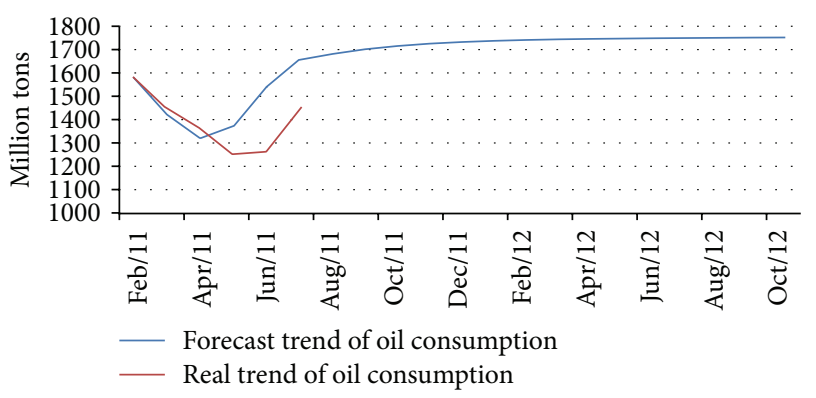

FIGURE 9: Real trend and forecast trend of oil demand.

TABLE 4: Comparison of the real data and the prediction result (million tons).

\begin{tabular}{lccccc}
\hline & March & April & May & June & July \\
\hline Real data & 1463.12 & 1372.15 & 1261.9 & 1272.11 & 1449.38 \\
Prediction & 1429.54 & 1330.6 & 1381.87 & 1547.57 & 1663.17 \\
Relative error & $-2.30 \%$ & $-3.03 \%$ & $9.51 \%$ & $21.65 \%$ & $14.75 \%$ \\
\hline
\end{tabular}

\subsection{Linkage Mechanisms}

3.4.1. Impact of Industrial Production on Oil Demand. As observed in Figure 9, the historical trend indicates that the oil demand reached the lowest level in May, 2011 and then significantly rebounded; while the forecast trend shows that Japan's oil demand reached the lowest level in April and increased steadily in coming months.

We make a comparison of the real data and the prediction derived from impact analysis, which is summarized in Table 4.

As indicated by Table 4, the overall trend of oil demand shown in the picture, in terms of impact depth and impact width, is essentially in line with the real trend; especially the predictions for decline in oil demand due to the error in March and April are merely $-2.30 \%$ and $-3.03 \%$. In contrast, the prediction for the increase of oil demand shows obvious divergence from the real data; but in July, this gap tends to be narrower. From the time perspective, in the predicted trend, the bottom point occurs in April, while in the real trend, the bottom point occurs in May. That is, the predicted trend reaches the bottom point one month ahead of time.

These divergences between the predicted trend and real data could be contributed to the following aspects: (i) Oil demand has a great association with the economic activities. The change of demand in the recovery phase is largely influenced by Japan's response to the crisis and the process of reconstruction work after the earthquake, which dominates the gap between the predicted trend and real data in May, June, and July.

(ii) The time horizon is relevant to the accuracy of prediction. In this case, if the time horizon is extended from "month" to "quarter," the results could prove to be better, because both predicted trend and real trend would indicate that the oil demand of Japan decreases in the first quarter and rebounds in the second quarter; the discrepancy is concealed. However, choosing "month" as the time horizon is suitable for this case, because the demand data is generally on a monthly basis statistics; it is difficult to get the Japanese daily or weekly demand data; what is more, using "quarter" as the time horizon makes the time span too long, which may lead to a neglect of the detailed change and undermine the accuracy of the predictions.

(iii) Our analysis and prediction are mainly based on industrial production and nuclear energy utilization. However, 3.11 earthquake is the largest one in Japan's history; its impact involves multiple areas, so its derivative events are surely not limited to these two factors. The difference between the amount of predicted oil demand and true oil demand is largely attributed to other derivative events which are left out in the analysis.

\section{Conclusions}

Investigating the impact caused by an emergency will be conducive for us to take effective measures and make timely judgments. This paper provides a standard procedure to assess the emergency impact in a quantitative way; the main emphasis is placed on illustrating the variation of the state of derivative events, which is demonstrated by the evolution path of impact. The evolution path is determined by impact depth and impact width, including three stages which are expressed in terms of specified functions.

From the results obtained in the case study, it seems that this methodology is suitable to assess and predict the impacts on primary derivative events and secondary derivative events. Compared to the studies carried out by former researchers, this evaluation procedure has made some progress in the quantitative analysis of emergency impact. In further research, we are committed to improve the accuracy of the assessment of evolution path. The emphasis will be put on the segmentation of each stage, for instance, the rising stage would be divided into different substages according to the variation rate of the impact depth, which is conducive to grasp the evolution process of derivative event in a more detailed way.

\section{Authors' Contribution}

Yuwen Chang and Yifan Gao contributed equally. 


\section{Acknowledgments}

The authors would like to thank the Editor of Journal of Applied Mathematics and some anonymous referees for their very valuable comments and suggestions. This work has been funded by Research Institute of Petroleum Exploration and Development (RIPED), PetroChina, through the RIPED project "Research on Oil Demand and Supply Based on Ecological Economics Theory" (Grant 2012Y-059) and funded by the RIPED project "Research on the Impacts of Major International Events on Oil Prices" (Grant 2010-A-26-26).

\section{References}

[1] T. Yamada, "A network flow approach to a city emergency evacuation planning," International Journal of Systems Science, vol. 27, no. 10, pp. 931-936, 1996.

[2] M. Pidd, F. N. de Silva, and R. W. Eglese, "A simulation model for emergency evacuation," European Journal of Operational Research, vol. 90, no. 3, pp. 413-419, 1996.

[3] C. W. Li, Public Crisis Management: Theory and Practice, Politics and Law University Press, Beijing, China, 2006.

[4] O. Ben-Avraham and D. Tabak, "Solution of an emergency air traffic control problem by differential dynamic programming," International Journal of Systems Science, vol. 9, no. 10, pp. 1167$1178,1978$.

[5] L. Ji, H. Chi, and A. Chen, Emergency Management, Beijing Higher Education Press, Beijing, China, 2006.

[6] H. Y. Tang, C. H. Tang, and C. L. Zhao, "A preemptiveresume stochastic scheduling model with disruption," System Engineering Theory and Practice, vol. 30, no. 4, pp. 751-757, 2010.

[7] Q. Shao, W. Weng, C. He, X. Ji, and H. Yuan, "Representation method for hierarchy network models for emergency analyses," Journal of Tsinghua University, vol. 49, no. 5, pp. 625-628, 2009.

[8] L. Cui, Q. Y. Zhong, Y. Z. Wang et al., "Research review of unconventional emergency's theory method based on context," Journal of Intelligence, vol. 30, no. 6, pp. 40-45, 2011.

[9] V. Cozzani, G. Gubinelli, G. Antonioni, G. Spadoni, and S. Zanelli, "The assessment of risk caused by domino effect in quantitative area risk analysis," Journal of Hazardous Materials, vol. 127, no. 1-3, pp. 14-30, 2005.

[10] X. Ji, W. Weng, and Q. Zhao, "Quantitative disaster chain risk analysis," Journal of Tsinghua University, vol. 49, no. 11, pp. 17491756, 2009.

[11] Y. B. Ju and A. H. Wang, "Research on the influence degree of rare event," Acta Armamentarii, vol. 30, no. 1, pp. 150-153, 2009.

[12] S. Fink, Crisis Management: The Plan to Deal with Emergencies, American Management Association, New York, NY, USA, 1986.

[13] Z. Y. Han, W. G. Weng, W. Zhang et al., "Backgrounds, targets, and organization of the major research plan 'study on unconventional emergencies management'” Bulletin of National Natural Science Foundation of China, no. 4, pp. 215-220, 2009.

[14] Y. Q. Zhang, M. Liu, and D. L. Zhang, "On the quantitative assessment of risk by Domino effect," Journal of Safety and Environment, vol. 8, no. 1, pp. 145-149, 2008.

[15] D. C. Huang and K. Q. Zhao, "Classifying method of critical paths in network planning including unexpected incident and its applications," Journal of Systems Engineering, vol. 16, no. 3, pp. 161-166, 2001.
[16] S. H. Qi and G. L. Le, "Theoretical analysis of emergent incidents: social capital perspective," Nankai Business Review, vol. 6, no. 6, pp. 22-27, 2003.

[17] Y. Y. Yu, H. Chi, and M. L. Qi, "Study on resource allocation problem of emergencies with infection," Chinese Journal of Management Science, vol. 16, no. 5, pp. 77-83, 2008.

[18] R. Vernon, "International investment and international trade in the product cycle," The Quarterly Journal of Economics, vol. 80, no. 2, pp. 190-207, 1966. 


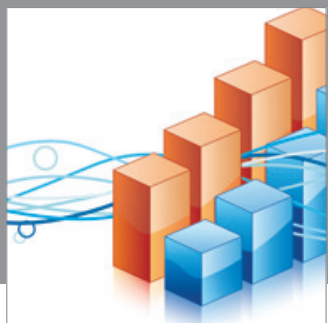

Advances in

Operations Research

mansans

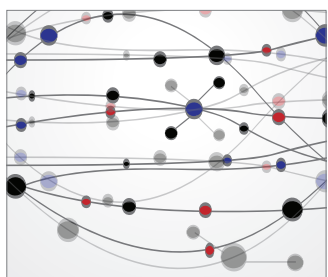

The Scientific World Journal
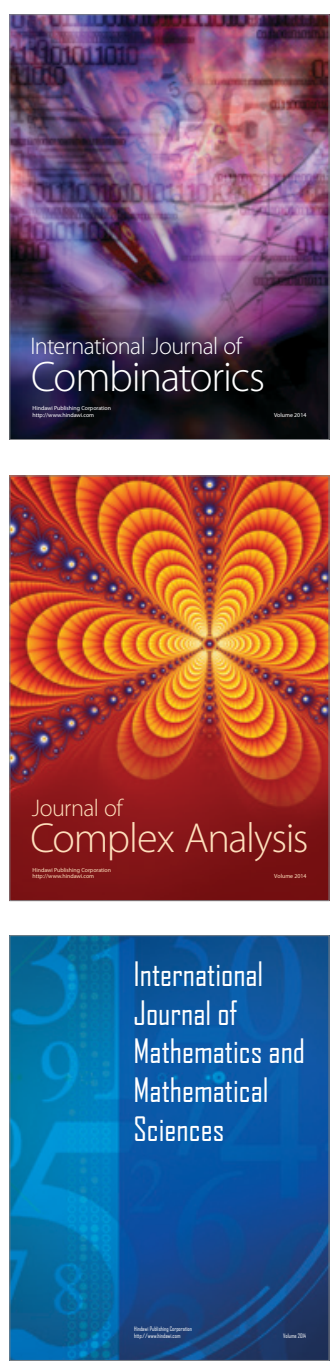
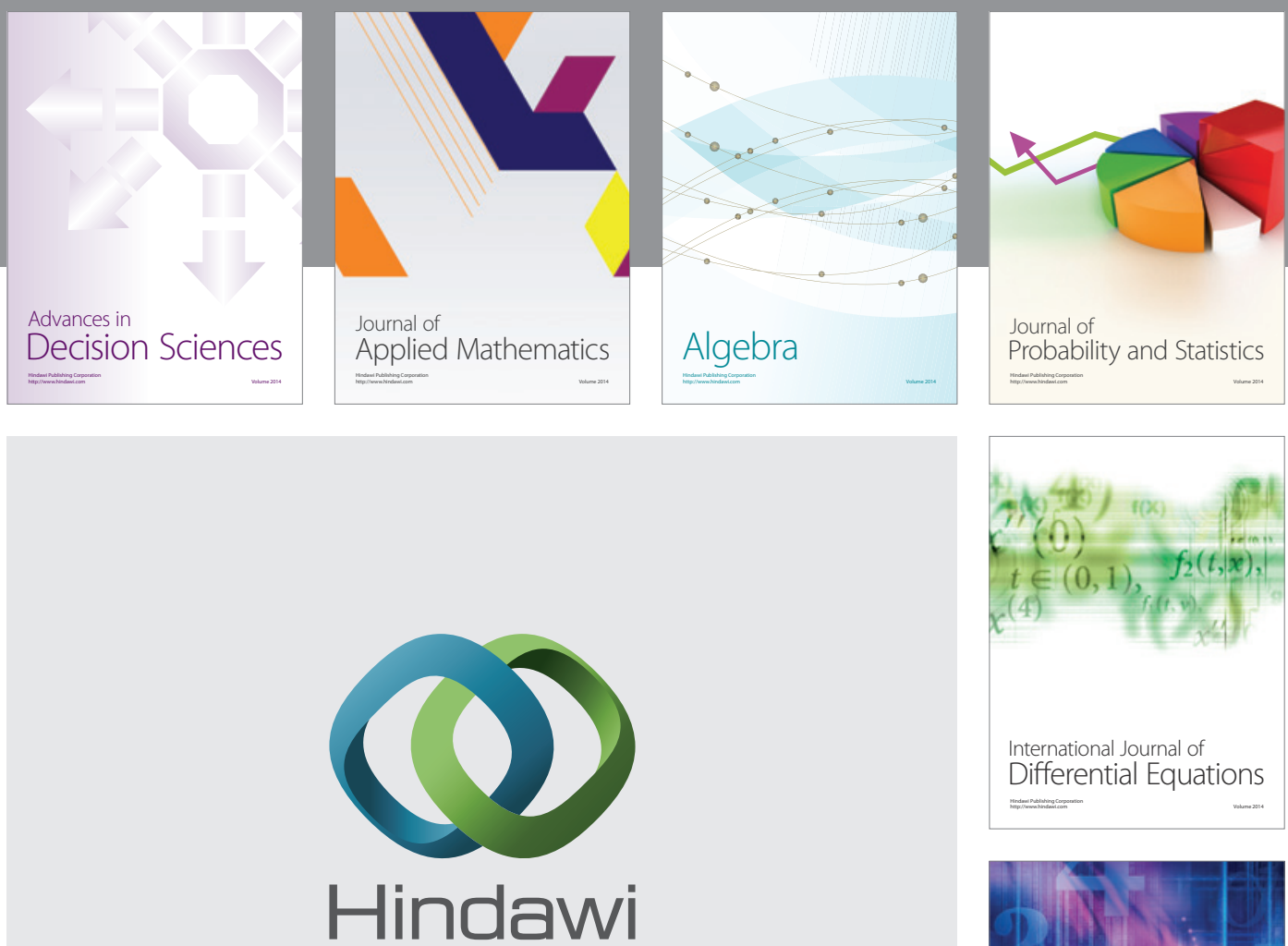

Submit your manuscripts at http://www.hindawi.com
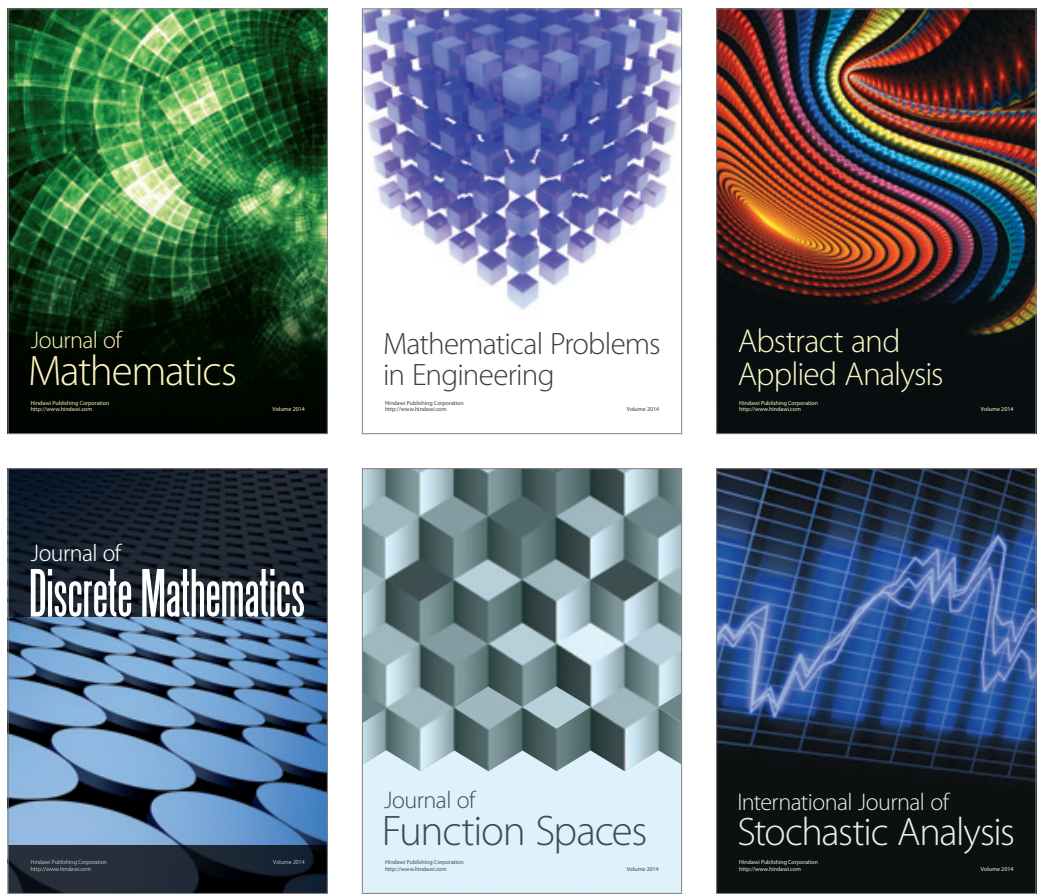

Journal of

Function Spaces

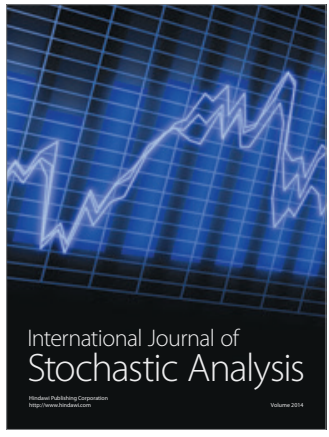

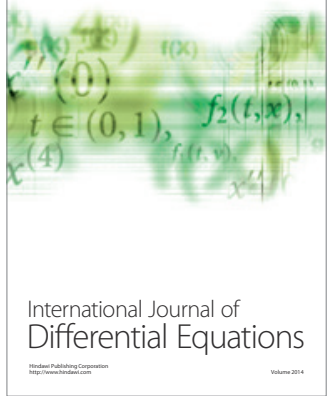
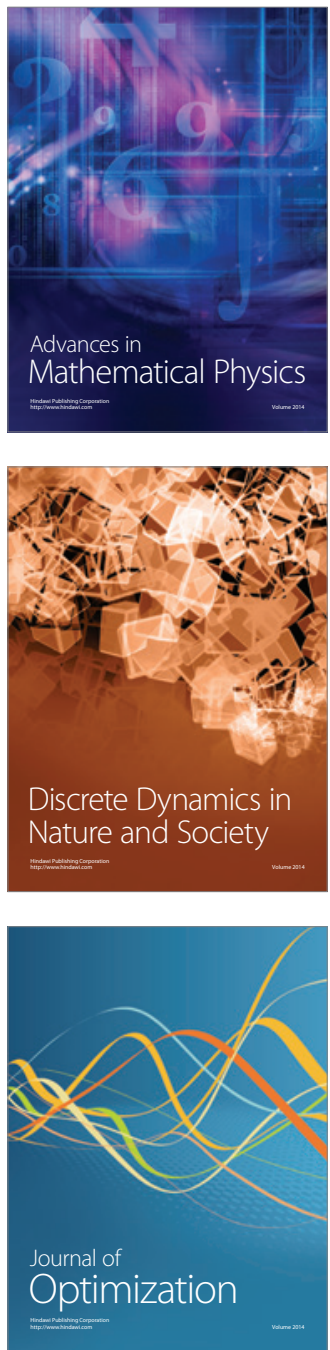